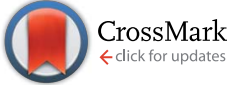

Cite this: Chem. Sci., 2017, 8, 2959

\title{
Redox-active triazatruxene-based conjugated microporous polymers for high-performance supercapacitors $\uparrow$
}

\author{
Xiang-Chun Li, ${ }^{a}$ Yizhou Zhang, ${ }^{\text {ab }}$ Chun-Yu Wang, ${ }^{a}$ Yi Wan, ${ }^{a}$ Wen-Yong Lai, ${ }^{* a b}$ \\ Huan Pang*c and Wei Huang*ab
}

Conjugated polymers (CPs) have been intensively explored for various optoelectronic applications in the last few decades. Nevertheless, CP based electrochemical energy storage devices such as supercapacitors remain largely unexplored. This is mainly owing to the low specific capacitance, poor structural/electrochemical stability, and low energy density of most existing CPs. In this contribution, a novel set of redox-active conjugated microporous polymers, TAT-CMP-1 and TAT-CMP-2, based on nitrogen-rich and highly conductive triazatruxene building blocks, were successfully designed and synthesized to explore their potential application as efficient and stable electrode materials for supercapacitors. Despite a moderate surface area of $88 \mathrm{~m}^{2} \mathrm{~g}^{-1}$ for TAT-CMP-1 and $106 \mathrm{~m}^{2} \mathrm{~g}^{-1}$ for TATCMP-2, exceptional specific capacitances of $141 \mathrm{~F} \mathrm{~g}^{-1}$ and $183 \mathrm{~F} \mathrm{~g}^{-1}$ were achieved at a current density of $1 \mathrm{~A} \mathrm{~g} \mathrm{~g}^{-1}$. The resulting polymers exhibited unusually high areal specific capacitance $\left(>160 \mu \mathrm{F} \mathrm{cm}{ }^{-2}\right)$, which is attributed to the pseudocapacitance resulting from redox-active structures with high nitrogen content. More importantly, the TAT-CMP-2 electrode exhibits excellent cycling stability: only 5\% capacitance fading is observed after 10000 cycles at a high current density of $10 \mathrm{~A} \mathrm{~g}^{-1}$, enabling the possible use of these materials as electrodes in electrochemical devices.

Received 18th December 2016
Accepted 30th January 2017

DOI: $10.1039 / c 6 s c 05532 j$

rsc.li/chemical-science appliances. ${ }^{\mathbf{1 3 - 1 6}}$ Like other electrochemical devices, electrode materials are the key to the increase of device performance. Compared with the major classes of electrode materials for supercapacitors (carbon-based materials, and metal oxides, etc.), CPs possess some unique advantages, such as a high voltage window and adjustable redox activity through easy chemical modification. This potential, however, has not been fully exploited yet, due to some shortcomings of CPs, most importantly related to their relatively low specific capacitance and cycling stability, as well as their limited redox reversibility. ${ }^{17-20}$

Hybridization of CPs with different heteroatoms such as nitrogen, oxygen, or boron atoms promises to overcome these limitations. ${ }^{21-23}$ of these heteroatoms, the introduction of nitrogen has shown the greatest progress since it not only enables the enhancement of conductivity, wettability, and electro-active surface area of the electrode, but also endows the electrode with pseudocapacitance and thus further improves their electrochemical performance. ${ }^{24,25}$ Compared with physical doping processes, the introduction of heteroatoms into CPs through chemical methods has received much less attention, despite the facile and versatile chemical modification potential of CPs, mainly due to the lack of suitable CPs with large capacitance.

Other than the introduction of heteroatoms, the increase of pore density also holds promise to enhance the capacitance of 
CPs. As a novel series of porous CPs, conjugated microporous polymers (CMPs) have most recently attracted increasing attention owing to their merits of permanent porosity, low density and strong covalent linkages. ${ }^{26-28}$ CMPs have thus emerged as a promising class of porous materials with huge application potential in gas storage and separation, heterogeneous catalysis, sensors, light harvesting, luminescence, and energy conversion. ${ }^{29-31}$ To explore the potential of CMPs as active electrode materials for supercapacitors, CMPs with varying structures have been investigated with limited success. $^{32,33}$ The relatively low conductivity and the limited chemical and oxidative stability of established CMP linkages, such as boroxines and boronate esters, however, appear to be the main obstacles. ${ }^{34}$

In this work, we developed a novel set of redox-active CMPs that show outstanding electrochemical performance which can be attributed to both the optimised pore distribution and the nitrogen heteroatom within its structure that can increase capacitance. Triazatruxene (TAT), a planar $\pi$-extended conjugated block with $C_{3}$ symmetry that can be considered as an overlapping framework of three carbazole units, was selected as the building block. Its nitrogen-rich feature and large $\pi$-conjugated planar structure are beneficial to increasing the electrical conductivity. Due to these features, it shows strong electron-donating and hole-transporting capabilities, enabling high-performance organic light emitting diodes, liquid crystal displays, organic photovoltaics, organic lasers, and fluorescent sensors. ${ }^{35-37}$ To the best of our knowledge, there is no report on TAT being explored for energy storage applications so far. To achieve larger capacitance and higher redox stability, imine bonds which are less susceptible to moisture than boroxine/ boronate ester bonds are introduced. In this way, we can overcome the low cycling stability and limited redox reversibility of traditional CPs as well as increase the specific capacitance, to afford a promising electrode material for electrochemical applications.

We report herein the syntheses of triazatruxene-based CMPs, TAT-CMP-1 and TAT-CMP-2, and their promising application in supercapacitors. Brunauer-Emmett-Teller (BET) models were applied for TAT-CMP-1 and TAT-CMP-2, where the calculated BET surface areas were $88 \mathrm{~m}^{2} \mathrm{~g}^{-1}$ and $106 \mathrm{~m}^{2} \mathrm{~g}^{-1}$, respectively. According to electrochemical measurements, TAT-CMP-1 and TAT-CMP-2 possessed a specific capacitance of $141 \mathrm{~F} \mathrm{~g}^{-1}$ and $183 \mathrm{~F} \mathrm{~g}^{-1}$ at $1.0 \mathrm{~A} \mathrm{~g}^{-1}$, respectively. The results were superior to those of most traditional nitrogen-doped carbon electrodes. ${ }^{38-40}$ They also exhibited very stable cycling performance in a threeelectrode system, and only 5\% capacitance decay for TAT-CMP-2 was observed after 10000 cycles at a high current density of $10 \mathrm{~A} \mathrm{~g}^{-1}$. These excellent results endow TAT-based CMPs with great potential for achieving high-performance and stable supercapacitors. In addition, the influence of the nitrogen content and molecular structure on the capacitive properties of the resulting materials were investigated, which sheds light on the rational design and development of efficient and stable electrode materials for supercapacitors and other related electrochemical devices.

\section{Results and discussion}

The synthetic procedures of TAT-CMP-1 and TAT-CMP-2 are depicted in Fig. 1. TATR was synthesized according to our previous work. ${ }^{\mathbf{4 1}}$ Direct nitration reaction of TATR with nitric acid in dichloromethane afforded TAT-3NO $\mathbf{N O}_{2}$ in $82 \%$ yield. Subsequent reduction with $\mathrm{N}_{2} \mathrm{H}_{4} \cdot \mathrm{H}_{2} \mathrm{O}$ using $\mathrm{Pd} / \mathrm{C}$ as a catalyst offered the key intermediate amine TAT-3 $\mathbf{N H}_{2}$ in a high yield of 73\%. TAT-CMP-1 and TAT-CMP-2 were synthesized under solvothermal conditions by condensation of TAT-3NH $\mathbf{N H}_{2}$ with PMDA or TPAL in a mixed solution of 1,4-dioxane and mesitylene followed by heating at $120{ }^{\circ} \mathrm{C}$ for 3 days, giving the solid powders in yields of $82 \%$ for TAT-CMP-1 and 85\% for TAT-CMP-2. These materials demonstrated no changes upon exposure to air, humidity, or organic solvents. They are insoluble in common solvents such as chloroform, toluene, xylene, tetrahydrofuran (THF), chlorobenzene, dimethyl sulfoxide (DMSO), $N, N$-dimethylformamide (DMF), $N, N$ dimethylacetamide (DMAc), and $N$-methylpyrrolidone (NMP), suggesting a hyper-cross-linked structure. Thermogravimetric analysis (TGA) of TAT-CMP-1 and TAT-CMP-2 showed high thermal stability with a decomposition temperature of $394{ }^{\circ} \mathrm{C}$ and $391{ }^{\circ} \mathrm{C}$ (Fig. S1 $\dagger$ ), respectively. In addition, no distinctive melting or crystallization transitions were observed during the DSC scans from room temperature to $250{ }^{\circ} \mathrm{C}$ (Fig. S2 $\dagger$ ), suggesting the amorphous properties of the resulting CMPs, which were further confirmed by powder X-ray diffraction (XRD) patterns (Fig. S3 $\dagger$ ). They exhibited a slight spike at $5.5^{\circ}$ and a broad peak at $22^{\circ}$, which revealed that they had fairly low crystallinity. Irregular stacking morphologies were observed using scanning electron microscopy (SEM) (Fig. S4 and S5 $\dagger$ ). The SEM measurements show that the surface morphologies of the samples are homogeneous, composed of loosely packed tiny particles. Moreover, the particles have irregular shapes with a rather rough surface. Transmission electron microscopy (TEM) reveals the presence of micro- and meso-pores that originate from the highly crosslinked molecular skeletons (Fig. S6 and S7†).

X-ray photoelectron spectroscopy (XPS, Fig. 2) and elemental analysis were conducted to further investigate the chemical nature of TAT-CMP-1 and TAT-CMP-2. XPS of TAT-CMP-1 shows a primary $\mathrm{C} 1 \mathrm{~s}$ peak at $284.8 \mathrm{eV}, \mathrm{N} 1 \mathrm{~s}$ peak at $400.2 \mathrm{eV}$ and $\mathrm{O} 1 \mathrm{~s}$ peak at 532.2 (Fig. 2a). TAT-CMP-2 has a dominant $\mathrm{C} 1 \mathrm{~s}$ peak at $284.8 \mathrm{eV}$, a stronger peak for $\mathrm{N} 1 \mathrm{~s}$ at $399.9 \mathrm{eV}$ and a much smaller signal for the $\mathrm{O} 1 \mathrm{~s}$ peak at $531.5 \mathrm{eV}$ (Fig. 2b). These peaks verify the integration of $\mathrm{N}$ atoms into these compounds (8.4\% $\mathrm{N}$ atomic ratio in TAT-CMP-1 and 9.7\% $\mathrm{N}$ atomic ratio in TAT-CMP-2, which are close to the elemental analysis results with $8.54 \% \mathrm{~N}$ in TAT-CMP-1 and $10.40 \%$ in TAT-CMP-2). From the XPS results of TAT-CMP-1 (Fig. 2c), we can see three $\mathrm{N} 1 \mathrm{~s}$ peaks, which represent three different sorts of nitrogen atoms including ternary nitrogen $(400.2 \mathrm{eV})$ from the $N$-hexyl carbazole moiety, quaternary nitrogen $(401.1 \mathrm{eV})$, and oxidised nitrogen $(403.0 \mathrm{eV}){ }^{42}$ For TAT-CMP-2 (Fig. 2d), the signal peaks at $399.9 \mathrm{eV}, 401.5 \mathrm{eV}$ and $402.7 \mathrm{eV}$ are assigned to the $N$-hexyl carbazole moiety, quaternary nitrogen, and oxidised nitrogen, respectively, while a new peak at $398.7 \mathrm{eV}$ appears, which is attributed to $\mathrm{C}=\mathrm{N}$ from the amides. ${ }^{43}$ 

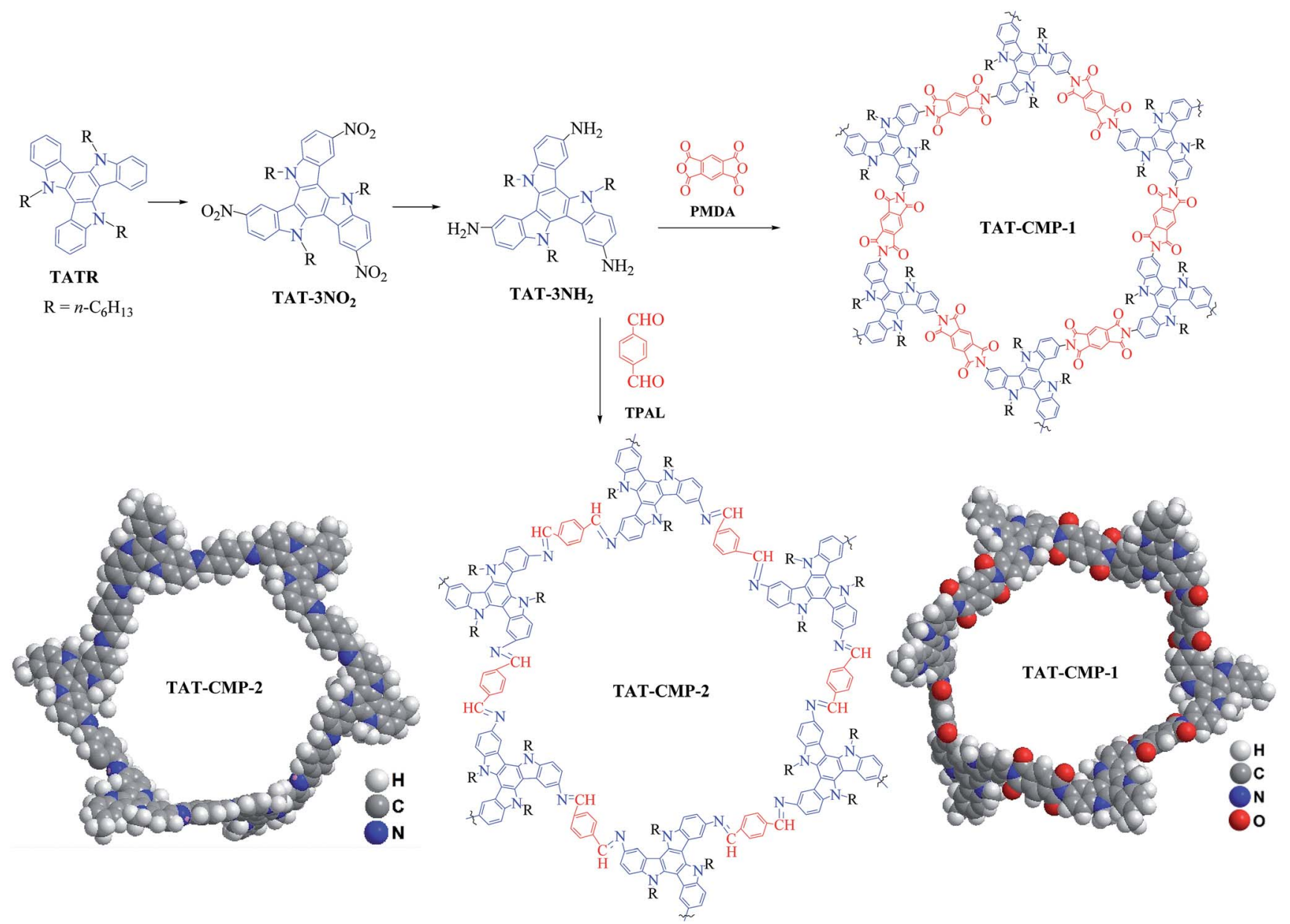

Fig. 1 Synthesis route and the three-dimensional view of TAT-CMP-1 and TAT-CMP-2 in an amorphous periodic cell (grey: carbon, white: hydrogen, blue: nitrogen, red: oxygen, and $n$-hexyl groups (R) are omitted for clarity).

The pore structure was evaluated by nitrogen sorption isotherms measured at $77 \mathrm{~K}$, which revealed that TAT-CMP-1 and TAT-CMP-2 exhibited type I and IV characteristics, consisting of both microporous and mesoporous structures. As shown in Fig. 3, the sorption isotherms exhibit a rise of uptake in the low relative pressure region $(<0.1)$, indicative of the presence of a substantial number of micropores. A slight sorption hysteresis can be observed over the whole range from 0.1 to 0.8 , which can be interpreted as the network swelling or restricted access of adsorbate molecules through a narrow pore opening. ${ }^{44}$ Moreover, when the relative pressure exceeds 0.8, they show a significant increase of nitrogen uptake, suggesting the presence of a macroporous structure, which can be interpreted as the interparticulate voids arising from the loose packing of small particles as observed in the SEM images. On the other hand, the desorption isotherms lie above the adsorption one to form an unclosed loop, displaying a typical desorption-adsorption hysteresis effect. The BET surface areas are evaluated to be 88 and $106 \mathrm{~m}^{2} \mathrm{~g}^{-1}$ for TAT-CMP-1 and TATCMP-2, respectively, which are comparable with those of other porous polymers. ${ }^{45}$ The results indicate that TAT-CMP-1 and TAT-CMP-2 are microporous polymers based on nitrogen-rich triazatruxene conjugated skeletons (Fig. S8†).
To evaluate the electrochemical performances of TAT-CMP-1 and TAT-CMP-2, a conventional three-electrode system was used, which consisted of a triazatruxene-based CMP working electrode (80 wt $\%$ TAT-CMP-1 or TAT-CMP-2, $15 \mathrm{wt} \%$ acetylene black and $5 \mathrm{wt} \%$ polytetrafluoroethylene (PTFE)), a saturated calomel electrode (SCE) as the reference electrode, a platinum electrode as the counter electrode, and $1.0 \mathrm{M} \mathrm{Na}_{2} \mathrm{SO}_{4}$ as the electrolyte.

Cyclic voltammetry (CV) curves for TAT-CMP-1 and TATCMP-2 at scan rates of $5 \mathrm{mV} \mathrm{s}^{-1}, 10 \mathrm{mV} \mathrm{s}^{-1}, 25 \mathrm{mV} \mathrm{s}^{-1}$ and $50 \mathrm{mV} \mathrm{s}^{-1}$ are shown in Fig. 4. The CV curves of TAT-CMP-1 and TAT-CMP-2 exhibit a nearly rectangular shape, which can be interpreted as the combination of a series of successive multiple surface redox reactions occurring during the charge/discharge process in the potential window of $-1-0 \mathrm{~V} v s$. $\mathrm{Hg} / \mathrm{HgO}{ }^{46}$ The multiple broad redox peaks constituting these almost rectangular curves indicate pseudocapacitive effects, which may be associated with the multiple nitrogen-containing moieties existing in the CMPs. ${ }^{47}$ It is implied that redox reactions have fast charging-discharging kinetics. Considering that the surface area of TAT-CMP-1 and TAT-CMP-2 is significantly lower $\left(88 \mathrm{~m}^{2} \mathrm{~g}^{-1}\right.$ and $\left.106 \mathrm{~m}^{2} \mathrm{~g}^{-1}\right)$ than activated carbon (typically 500$\left.3000 \mathrm{~m}^{2} \mathrm{~g}^{-1}\right)$, the capacitance per surface area reaches 160 

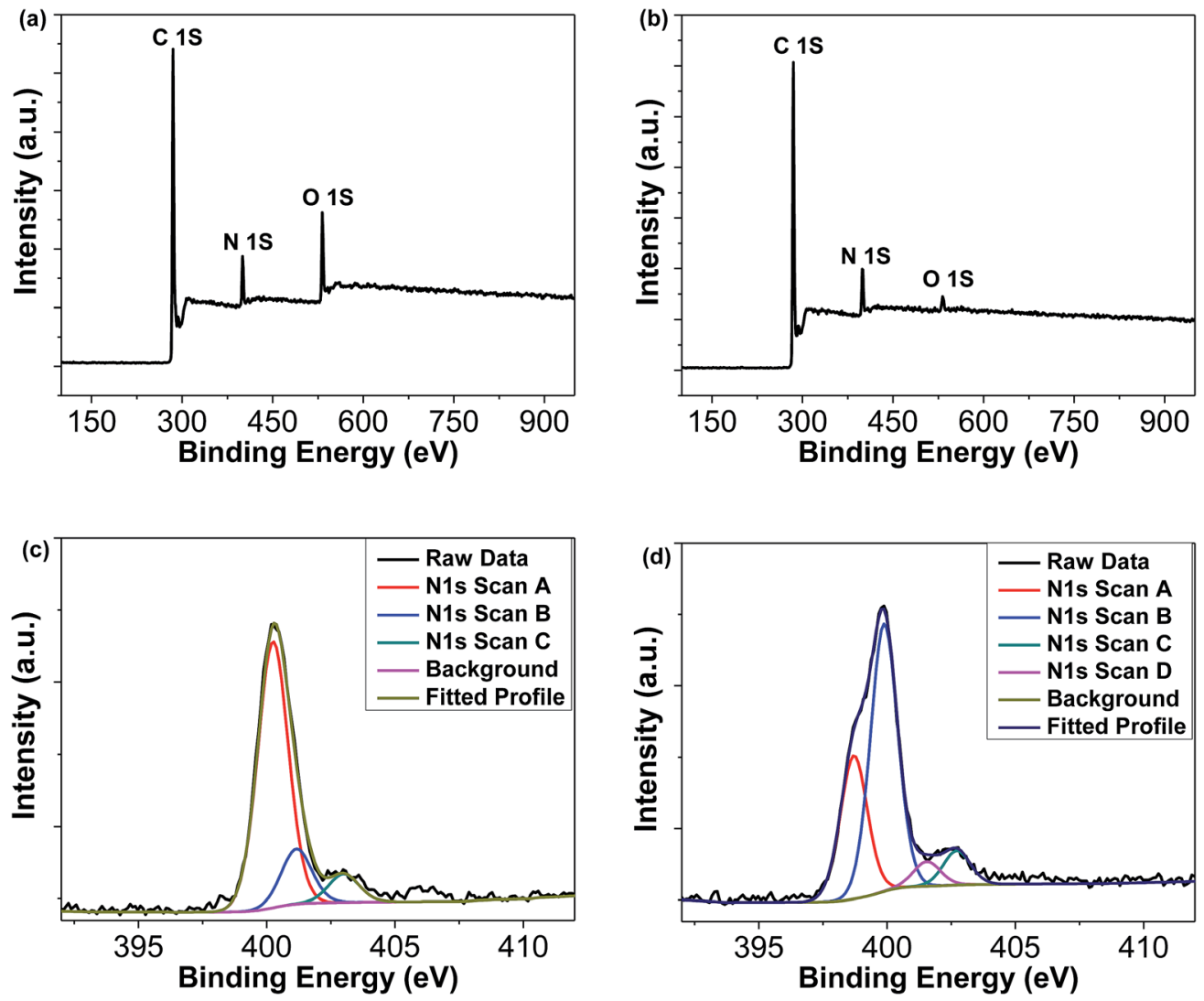

Fig. 2 XPS spectra for the survey scans of (a) TAT-CMP-1 and (b) TAT-CMP-2, and the N 1s core-level spectra of (c) TAT-CMP-1 and (d) TATCMP-2.

$\mu \mathrm{F} \mathrm{cm}{ }^{-2}$ for TAT-CMP-1 and $173 \mu \mathrm{F} \mathrm{cm}^{-2}$ for TAT-CMP-2, much higher than the theoretical capacitance of EDLCs (1-25 $\left.\mu \mathrm{F} \mathrm{cm}{ }^{-2}\right){ }^{48}$ To verify the faradaic process, the XPS results of TAT-CMP-1 and TAT-CMP-2 samples were investigated using CV scanning. Particularly, XPS results at different potentials (from $0 \mathrm{~V}$ to $-0.5 \mathrm{~V},-1.0,-1.5 \mathrm{~V}$, and $-2.0 \mathrm{~V}$ ) in the second $\mathrm{CV}$ scanning were recorded. The results are depicted in Fig. S9$\mathrm{S} 12 \dagger$ in comparison with those recorded before CV scanning (ESI $\dagger$ ). The key data are summarized in Table S1. $\dagger$ In the XPS spectra, four $\mathrm{N}$ 1s peaks represent the four different sorts of nitrogen atoms including iminic nitrogen $(-\mathrm{C}=\mathrm{N}-, 397.6 \pm$ $0.2 \mathrm{eV}$ ) from the Schiff base, ternary nitrogen $(400.1 \pm 0.2 \mathrm{eV})$ from the $N$-hexyl carbazole moiety, quaternary nitrogen $(401.1 \pm$ $0.2 \mathrm{eV})$, and oxidized nitrogen $(402.8 \pm 0.2 \mathrm{eV}) .{ }^{42,43}$ For TATCMP-1, the $\mathrm{N}$ 1s peak of quaternary nitrogen (401.1 eV) was absent after the negative scanning process from $0 \mathrm{~V}$ to $-0.5 \mathrm{~V}$. The $\mathrm{N}$ 1s core-level spectra are similar with a single peak after CV scanning from $0 \mathrm{~V}$ to $-1.0 \mathrm{~V},-1.5 \mathrm{~V}$, and $-2.0 \mathrm{~V}$, but the $\mathrm{N} 1 \mathrm{~s}$ peaks of quaternary nitrogen $(401.1 \mathrm{eV})$ and oxidized nitrogen $(403.0 \mathrm{eV})$ both disappeared. This illustrates that the successive multiple reduction processes occur on the $\mathrm{N}$ atoms of TAT-CMP1. Likewise, for TAT-CMP-2, the $\mathrm{N}$ 1s peaks of quaternary nitrogen (401.5 eV) and oxidized nitrogen (402.7 eV) disappeared due to the reduction process with a negative scanning voltage beyond $-1.0 \mathrm{~V}$. Obviously, the capacitance is mainly from the contribution of pseudocapacitance, which is due to the redox reaction mechanisms by the redox-active structures with a high concentration of $\mathrm{N}$ functional groups. Comparing Fig. $3 \mathrm{a}$ with $3 \mathrm{~b}$, the area under the CV curve for TAT-CMP-2 is apparently larger than that of TAT-CMP-1, demonstrating that TATCMP-2 has higher capacitance than TAT-CMP-1, which possibly results from the higher nitrogen content, larger specific surface area and appropriate pore size distribution.

Galvanostatic charge-discharge experiments were carried out to further validate the above observation (Fig. 5a and b). On the one hand, it is clear that the charge and discharge curves at current densities from $1.0 \mathrm{~A} \mathrm{~g}^{-1}$ to $10 \mathrm{~A} \mathrm{~g}^{-1}$ show symmetric features with a fairly linear slope, which suggests that fast ion transport and quick electron propagation occur within these CMP electrodes. On the other hand, the TAT-CMP-2 electrode displays the highest specific capacitance, which is in good agreement with the above $\mathrm{CV}$ results. The considerable variations in specific capacitance values, which are extracted from the discharge slopes and calculated based on the active material, distinctly reveal that the electrochemical performance is closely related to the nitrogen content. For TAT-CMP-1, the calculated specific capacitances are 141, 132, 115, and $99 \mathrm{~F} \mathrm{~g}^{-1}$ at current densities of $1,2,5$, and $10 \mathrm{~A} \mathrm{~g}^{-1}$, respectively. However, for the higher nitrogen content TAT-CMP-2, the calculated specific capacitances are 183, 173, 158, and $137 \mathrm{~F} \mathrm{~g}^{-1}$ at current densities of $1,2,5$, and $10 \mathrm{~A} \mathrm{~g}^{-1}$, respectively (Fig. S13†). More interestingly, the capacitive value of TAT-CMP- 

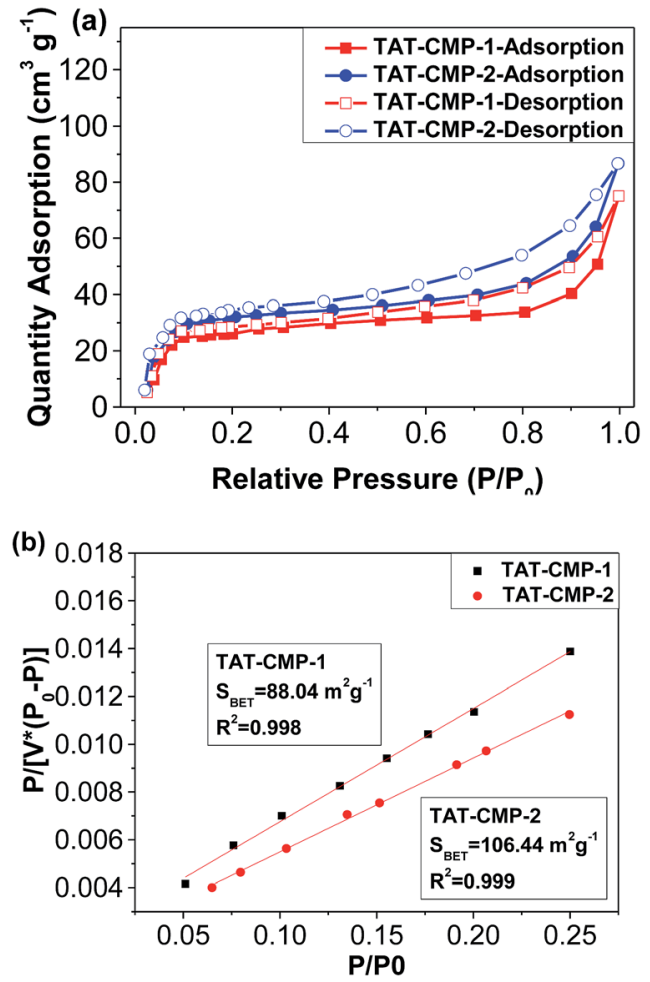

Fig. 3 (a) Nitrogen gas adsorption and desorption isotherms and (b) the BET plots of TAT-CMP-1 and TAT-CMP-2.
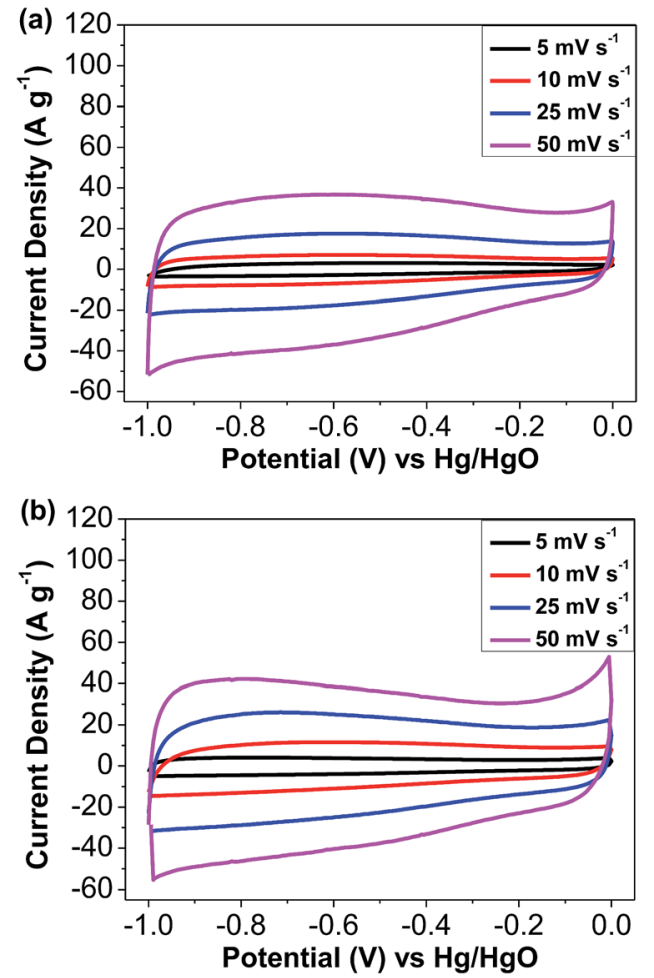

Fig. 4 Cyclic voltammetry curves of (a) TAT-CMP-1 and (b) TAT-CMP2 at different scan rates.
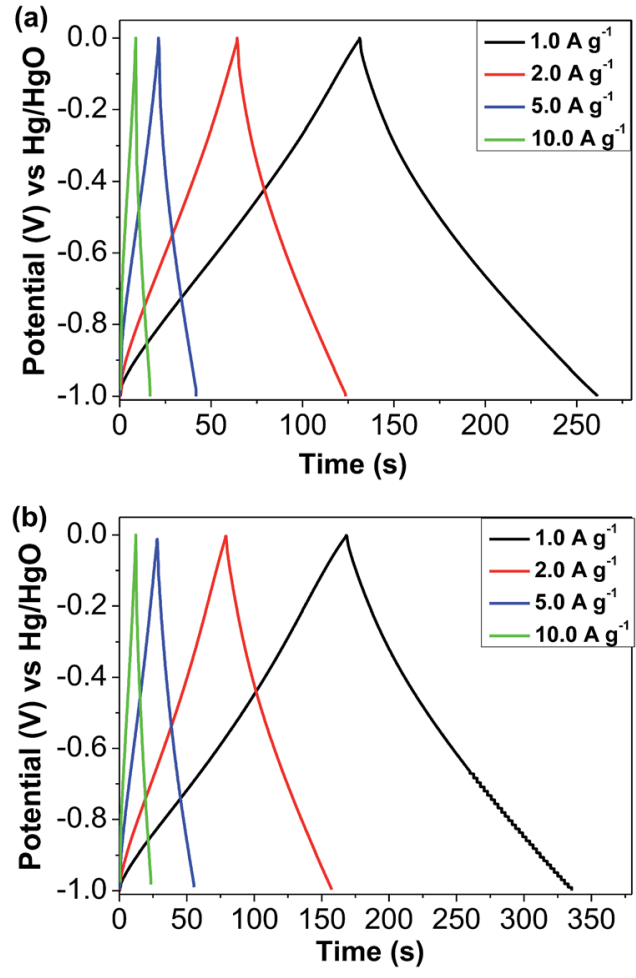

Fig. 5 Galvanostatic charge-discharge curves of (a) TAT-CMP-1 and (b) TAT-CMP-2 at different current densities.

1 and TAT-CMP-2 is still maintained above $110 \mathrm{~F} \mathrm{~g}^{-1}$ at a high current density of $5 \mathrm{~A} \mathrm{~g}^{-1}$, suggesting that such a prominent capacitive performance can be maintained under a high power density operation. Specifically, when the nitrogen content increases, the specific capacitance of TAT-CMP-2 at a current density of $1.0 \mathrm{~A} \mathrm{~g}^{-1}$ increases by nearly $30 \%$. Notably, the remarkable specific capacitance of TAT-CMP-2 is even superior to those of most previously reported porous materials with larger surface areas (Table S1 $\dagger$ ), such as two-dimensional covalent organic frameworks $\left(48 \mathrm{~F} \mathrm{~g}^{-1}\right.$ at $0.1 \mathrm{~A} \mathrm{~g}^{-1}, S_{\mathrm{BET}}=1124$ $\left.\mathrm{m}^{2} \mathrm{~g}^{-1}\right),{ }^{49}$ defect-engineered carbon nanotubes $\left(C=98 \mathrm{~F} \mathrm{~g}^{-1}\right.$ at $\left.1 \mathrm{~A} \mathrm{~g}^{-1}, S_{\text {BET }}=988 \mathrm{~m}^{2} \mathrm{~g}^{-1}\right),{ }^{38}$ nitrogen-doped hierarchical porous carbon nanosheets $\left(C=128 \mathrm{~F} \mathrm{~g}^{-1}\right.$ at $0.1 \mathrm{~A} \mathrm{~g}^{-1}, S_{\mathrm{BET}}=$ $\left.1735 \mathrm{~m}^{2} \mathrm{~g}^{-1}\right),{ }^{39}$ nitrogen-doped carbon nanoparticles $(C=84$ $\mathrm{F} \mathrm{g}^{-1}$ at $\left.1 \mathrm{~A} \mathrm{~g}^{-1}, S_{\mathrm{BET}}=365.3 \mathrm{~m}^{2} \mathrm{~g}^{-1}\right),{ }^{40}$ sulfur and nitrogen dual-doped porous carbon materials $\left(C=129 \mathrm{~F} \mathrm{~g}^{-1}\right.$ at $10 \mathrm{~A} \mathrm{~g}^{-1}$, $\left.S_{\mathrm{BET}}=655.4 \mathrm{~m}^{2} \mathrm{~g}^{-1}\right),{ }^{50}$ nitrogen/sulfur co-doped mesoporous carbon $\left(C=160 \mathrm{~F} \mathrm{~g}^{-1}\right.$ at $\left.1 \mathrm{~A} \mathrm{~g}^{-1}, S_{\mathrm{BET}}=1161 \mathrm{~m}^{2} \mathrm{~g}^{-1}\right),{ }^{51}$ and copolymer-templated nitrogen-enriched porous carbons $(C=$ $166 \mathrm{~F} \mathrm{~g}^{-1}$ at $\left.0.1 \mathrm{~A} \mathrm{~g}^{-1}, S_{\mathrm{BET}}=500 \mathrm{~m}^{2} \mathrm{~g}^{-1}\right) .^{52}$

The stability of TAT-CMP-1 and TAT-CMP-2 was tested using cycling experiments. As demonstrated in Fig. 6, they showed little capacitance decay (17\% for TAT-CMP-1 and $5 \%$ for TATCMP-2) after 500 cycles and exhibited almost no changes over 10000 charge-discharge cycles at a high current density of $10 \mathrm{~A} \mathrm{~g}^{-1}$. In particular, TAT-CMP-2 exhibited better performance stability than TAT-CMP-1 without any deterioration. That is, TAT-CMP-1 and TAT-CMP-2 outperform supercapacitors with inorganic electrodes, including ruthenium 


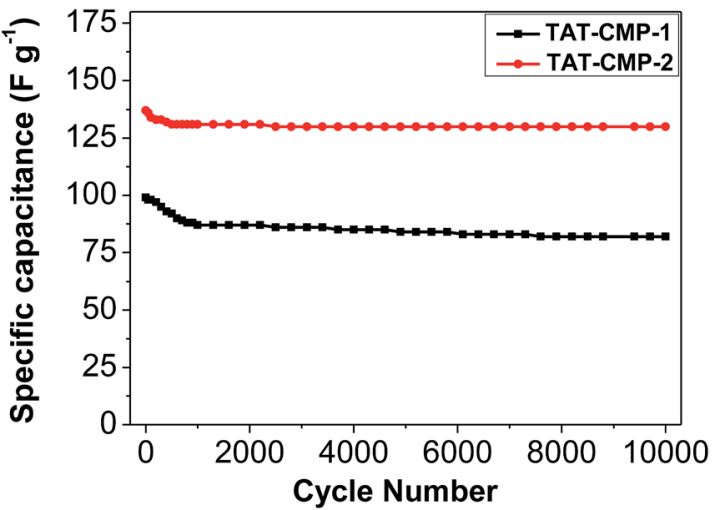

Fig. 6 The relationship of the specific capacitance against cycling number for TAT-CMP-1 and TAT-CMP-2 with a current density of 10 $\mathrm{A} \mathrm{g}^{-1}$ after 10000 cycles.

oxide that usually suffers from a decrease in capacitance after a few cycles. Therefore, the CMPs endow TAT-CMP-1 and TATCMP-2 with not only large capacitance, and high power and energy densities, but also an excellent cycling life.

\section{Conclusions}

In summary, a novel set of redox-active CMPs based on nitrogenrich and $\pi$-conjugated planar triazatruxene building blocks have been successfully designed, synthesized, and explored as efficient and stable electrode materials for high-performance supercapacitors. The nitrogen groups played a crucial role in inducing pseudocapacitance by improving the charge mobility of the CMPs as well as introducing negative charges on the polymer surface, which is presumed to result in ion doping/dedoping similar to that observed in $\mathrm{N}$-doped porous carbon materials. Due to the appropriate porous structure and high $\mathrm{N}$ content, the CMPs show a high specific capacitance of $141 \mathrm{~F} \mathrm{~g}^{-1}$ and $183 \mathrm{~F} \mathrm{~g}^{-1}$ at a current density of $1 \mathrm{~A} \mathrm{~g}^{-1}$ for TAT-CMP-1 and TAT-CMP-2, respectively. They exhibit unusually high capacitance per unit surface area $\left(>160 \mu \mathrm{F} \mathrm{cm}^{-2}\right.$ ) which is among the highest values obtained for CMP supercapacitors. Moreover, they manifest excellent reversibility with cycling efficiencies of $95 \%$ and $83 \%$ after 10000 cycles at a high current density of $10 \mathrm{~A} \mathrm{~g}^{-1}$. The good supercapacitor performance, clearly related to the unique nitrogen-rich properties and porous structure as shown in this work, suggests that a valuable strategy for improving the electrochemical performance is by specifically tuning the nitrogen content via a chemical doping method. This study has demonstrated the very promising potential of nitrogen-rich triazatruxene-based $\pi$-CMPs for applications in high-performance energy storage devices.

\section{Acknowledgements}

We acknowledge financial support from the National Key Basic Research Program of China (973 Program, 2014CB648300), National Natural Science Foundation of China (21422402, 21674050, 61136003, 21671170), Natural Science Foundation of Jiangsu Province (BK20140060, BK20130037, BM2012010), China Scholarship Council (201508320254), Program for
Jiangsu Specially-Appointed Professors (RK030STP15001), Innovation Project of Jiangsu Province (KYLX15_0845), Program for New Century Excellent Talents in University (NCET-13-0872, NCET-13-0645), Specialized Research Fund for the Doctoral Program of Higher Education (20133223110008), Synergetic Innovation Center for Organic Electronics and Information Displays, Priority Academic Program Development of Jiangsu Higher Education Institutions (PAPD), NUPT “1311 Project”, Six Talent Plan (2012XCL035, 2015XCL030), 333 Project (BRA2015374) and Qing Lan Project of Jiangsu Province.

\section{Notes and references}

1 X. Guo, M. Baumgarten and K. Müllen, Prog. Polym. Sci., 2013, 38, 1832-1908.

2 Z. An, C. Zheng, Y. Tao, R. Chen, H. Shi, T. Chen, Z. Wang, H. Li, R. Deng, X. Liu and W. Huang, Nat. Mater., 2015, 14, 685-690.

3 J.-J. Adjizian, P. Briddon, B. Humbert, J.-L. Duvail, P. Wagner, C. Adda and C. Ewels, Nat. Commun., 2014, 5, 5842 .

4 Y. Yao, H. Dong and W. Hu, Polym. Chem., 2013, 4, 51975205.

5 L.-H. Xie, C.-R. Yin, W.-Y. Lai, Q.-L. Fan and W. Huang, Prog. Polym. Sci., 2012, 37, 1192-1264.

6 L. Dou, Y. Liu, Z. Hong, G. Li and Y. Yang, Chem. Rev., 2015, 115, 12633-12665.

7 R. Tautz, E. Da Como, T. Limmer, J. Feldmann, H.-J. Egelhaaf, E. Von Hauff, V. Lemaur, D. Beljonne, S. Yilmaz and I. Dumsch, Nat. Commun., 2012, 3, 970.

8 J. Xie, C. Zhao, Z. Lin, Z.-Q. Lin, P.-Y. Gu and Q. Zhang, Chem.-Asian J., 2016, 11, 1489-1511.

9 N. Casado, G. Hernández, H. Sardon and D. Mecerreyes, Prog. Polym. Sci., 2016, 52, 107-135.

10 H. Yin and Z. Tang, Chem. Soc. Rev., 2016, 45, 4873-4891.

11 S. Zhao, H. Yin, L. Du, L. He, K. Zhao, L. Chang, G. Yin, H. Zhao, S. Liu and Z. Tang, ACS Nano, 2014, 8, 12660-12668.

12 J. Wu, X. Rui, C. Wang, W.-B. Pei, R. Lau, Q. Yan and Q. Zhang, Adv. Energy Mater., 2015, 5, 1402189.

13 Y.-Z. Zhang, Y. Wang, T. Cheng, W.-Y. Lai, H. Pang and W. Huang, Chem. Soc. Rev., 2015, 44, 5181-5199.

14 Y. Z. Zhang, T. Cheng, Y. Wang, W.-Y. Lai, H. Pang and W. Huang, Adv. Mater., 2016, 26, 5242-5248.

15 H. Pang, Y.-Z. Zhang, Z. Run, W.-Y. Lai and W. Huang, Nano Energy, 2015, 17, 339-347.

16 J. Xie and Q. Zhang, J. Mater. Chem. A, 2016, 4, 7091-7106.

17 C. Janáky and K. Rajeshwar, Prog. Polym. Sci., 2015, 43, 96135.

18 G. Wang, L. Zhang and J. Zhang, Chem. Soc. Rev., 2012, 41, 797-828.

19 A. M. Khattak, Z. A. Ghazi, B. Liang, N. A. Khan, A. Iqbal, L. Li and Z. Tang, J. Mater. Chem. A, 2016, 4, 16312-16317.

20 J. Wu, X. Rui, G. Long, W. Chen, Q. Yan and Q. Zhang, Angew. Chem., Int. Ed., 2015, 54, 7354-7358.

21 M. Enterría, M. Pereira, J. Martins and J. Figueiredo, Carbon, 2015, 95, 72-83. 
22 Y. Deng, Y. Xie, K. Zou and X. Ji, J. Mater. Chem. A, 2016, 4, 1144-1173.

23 D. Hulicova-Jurcakova, M. Seredych, G. Q. Lu and T. J. Bandosz, Adv. Funct. Mater., 2009, 19, 438-447.

24 J. P. Paraknowitsch and A. Thomas, Energy Environ. Sci., 2013, 6, 2839-2855.

25 K. N. Wood, R. O'Hayre and S. Pylypenko, Energy Environ. Sci., 2014, 7, 1212-1249.

26 Y. Xu, S. Jin, H. Xu, A. Nagai and D. Jiang, Chem. Soc. Rev., 2013, 42, 8012-8031.

27 F. Vilela, K. Zhang and M. Antonietti, Energy Environ. Sci., 2012, 5, 7819-7832.

28 A. I. Cooper, Adv. Mater., 2009, 21, 1291-1295.

29 C. Gu, N. Huang, Y. Chen, H. Zhang, S. Zhang, F. Li, Y. Ma and D. Jiang, Angew. Chem., Int. Ed., 2016, 55, 3049-3053.

30 Y. Xie, T.-T. Wang, X.-H. Liu, K. Zou and W.-Q. Deng, Nat. Commun., 2013, 4, 1960.

31 J. Guo, Y. Xu, S. Jin, L. Chen, T. Kaji, Y. Honsho, M. A. Addicoat, J. Kim, A. Saeki and H. Ihee, Nat. Commun., 2013, 4, 2736.

32 Y. Kou, Y. Xu, Z. Guo and D. Jiang, Angew. Chem., Int. Ed., 2011, 123, 8912-8916.

33 X. Liu, Y. Xu and D. Jiang, J. Am. Chem. Soc., 2012, 134, 87388741.

34 D. Wu, F. Xu, B. Sun, R. Fu, H. He and K. Matyjaszewski, Chem. Rev., 2012, 112, 3959-4015.

35 W.-Y. Lai, Q. Y. He, R. Zhu, Q. Q. Chen and W. Huang, Adv. Funct. Mater., 2008, 18, 265-276.

36 E. M. García-Frutos, U. K. Pandey, R. Termine, A. Omenat, J. Barberá, J. L. Serrano, A. Golemme and B. Gómez-Lor, Angew. Chem., Int. Ed., 2011, 123, 7537-7540.

37 X.-C. Li, C.-Y. Wang, W.-Y. Lai and W. Huang, J. Mater. Chem. C, 2016, 4, 10574-10587.

38 Y. S. Yun, G. Yoon, K. Kang and H.-J. Jin, Carbon, 2014, 80, 246-254.
39 X. Yu, J. Zhao, R. Lv, Q. Liang, C. Zhan, Y. Bai, Z.-H. Huang, W. Shen and F. Kang, J. Mater. Chem. A, 2015, 3, 1840018405.

40 L.-P. Lv, Z.-S. Wu, L. Chen, H. Lu, Y.-R. Zheng, T. Weidner, X. Feng, K. Landfester and D. Crespy, RSC Adv., 2015, 5, 50063-50069.

41 X.-C. Li, C.-Y. Wang, Y. Wan, W.-Y. Lai, L. Zhao, M.-F. Yin and W. Huang, Chem. Commun., 2016, 52, 2748-2751.

42 J.-S. M. Lee, T.-H. Wu, B. M. Alston, M. E. Briggs, T. Hasell, C.-C. Hu and A. I. Cooper, J. Mater. Chem. A, 2016, 4, 76657673.

43 L.-J. Feng, Q. Chen, J.-H. Zhu, D.-P. Liu, Y.-C. Zhao and B.-H. Han, Polym. Chem., 2014, 5, 3081-3088.

44 X. Ding and B. H. Han, Angew. Chem., Int. Ed., 2015, 54, 6536-6539.

45 Y.-F. Xie, S.-Y. Ding, J.-M. Liu, W. Wang and Q.-Y. Zheng, J. Mater. Chem. C, 2015, 3, 10066-10069.

46 T. Zhai, X. Lu, F. Wang, H. Xia and Y. Tong, Nanoscale Horizons, 2016, 1, 109-124.

47 T. Lin, I.-W. Chen, F. Liu, C. Yang, H. Bi, F. Xu and F. Huang, Science, 2015, 350, 1508-1513.

48 B. E. Conway, Electrochemical supercapacitors: scientific fundamentals and technological applications, Springer Science \& Business Media, 2013.

49 C. R. DeBlase, K. E. Silberstein, T.-T. Truong, H. C. D. Abruña and W. R. Dichtel, J. Am. Chem. Soc., 2013, 135, 16821-16824.

50 G. Xu, J. Han, B. Ding, P. Nie, J. Pan, H. Dou, H. Li and X. Zhang, Green Chem., 2015, 17, 1668-1674.

51 S. Zhang, A. Ikoma, K. Ueno, Z. Chen, K. Dokko and M. Watanabe, ChemSusChem, 2015, 8, 1608-1617.

52 M. Zhong, E. K. Kim, J. P. McGann, S.-E. Chun, J. F. Whitacre, M. Jaroniec, K. Matyjaszewski and T. Kowalewski, J. Am. Chem. Soc., 2012, 134, 14846-14857. 